\title{
Buddhism and Psychotherapy
}

\author{
Su-Yeon Kim \\ Department of Psychiatry, Yong-In Mental Hospital, Yongin, Korea
}

\section{불교와 정신치료}

김 수 연

용인정신병원 정신건강의학과

Buddhism and Psychotherapy focus on alleviating mental suffering through a detailed investigation of mental process. Therefore Buddhism and Psychotherapy overlap each other in the theory and in practice. Historically there are many attempts to collaborate between Buddhism and psychology by a variety of renowned psychoanalysts such as Carl Jung, Erich Fromm, Karen Horney, and Mark Epstein et al. I reviewed Buddhism's approach to the self which is described as "no-self". Sense of the self arises from different conditions, there isn't a permanent and solid self. An expanded understanding of the self based on Buddhism is not contradictory to modern psychology and deepens the therapeutic potential of no-self. In practice, Buddhism and psychotherapy roughly share the similar method in some aspect to approach the inner mind. But the next step to deal with these materials is definitely different. In this article I never attempt to view Buddhism through the term of psychotherapy and to integrate two fields. The earnest introspection and considerate academic attitude are necessary to collaborate between Buddhism and psychotherapy without losing the essence of each other.

Psychoanalysis 2016;27(4):133-137

KEY WORDS: Buddhism · Psychotherapy · Meditation.

Received: September 9, 2016 Revised: October 1, 2016 Accepted: October 3, 2016

Address for correspondence: Su-Yeon Kim, MD

Department of Psychiatry, Yong-In Mental Hospital, 940 Jungbu-daero, Giheung-gu, Yongin 17089, Korea

Tel: +82-31-288-0114, Fax: +82-31-288-0184, E-mail: nomad72@naver.com

\section{서 론}

서양의 심리학과 정신분석, 정신의학계에서는 수십 년 전 부터 동양의 종교인 불교에 관심을 갖고 연구를 해왔다. 이 에 기반한 치료기법이 등장하여 정신치료의 한 영역이 된 것 도 있다. 이런 적용은 한국을 포함한 불교 문화권에서는 도 리어 종교라는 틀에 묶여 불교의 심리치유적 측면을 간과하 고 있었다는 반성을 하게 한다. 미국을 중심으로 현재 심리 학이나 정신의학의 흐름을 살피자면, Soyen Shaky 선사가 미국에 처음 불교를 소개한 것이 1905년이고, 프로이트가 미국의 Clark 대학에서 강연한 것이 1909년이므로 이 두 가지 일이 거의 비슷한 시기에 소개된 것은 흥미롭다(Porter 2004). 비록 같은 시기에 소개가 되었지만, 불교와 정신의학의 교류

This is an Open Access article distributed under the terms of the Creative Commons Attribution Non-Commercial License (http://creativecommons.org/licenses/by-nc/3.0) which permits unrestricted non-commercial use, distribution, and reproduction in any medium, provided the original work is properly cited.
가 처음부터 활발한 것은 아니었다. 기록에 따르면 스즈키 (Suzuki) 선사와 에리히 프롬(Erich Fromm), 카렌 호나이 (Karen Horney) 등 정신분석가들 사이에 개인적 교류가 있 었고, 두 영역에 대한 이해의 장을 확장시키는 데 많은 기여 를 하였다. 점차 수행이나 불교에 대한 이해가 깊은 정신의학 자들이 생겨나고 불교계에서도 의학, 과학과 접목하여 붓다 의 가르침을 현대에 맞는 방법으로 전하고자 하는 움직임이 생겨나면서 어느새 불교는 서양의 심리학, 정신의학에서 상 당히 중요한 한 부분을 차지하게 되었다(Aich 2013; Michalon 2001).

붓다는 그 자신의 마음을 관찰하여 통찰을 얻고 고통으로 부터 벗어나는 방법을 제시함으로써 마음을 다스리는 이론 과 방법의 체계를 만들었다. 붓다의 기본 가르침인 사성제는 1) 고(苦): 괴로움, 2) 집(集): 괴로움의 발생, 3) 멸(滅): 괴로 움의 소멸, 4) 도(道): 괴로움의 소멸에 이르는 길로 요약할 수 있고, 이는 현대의학의 치료에 비유하면, 고통을 해소하는 데 목적을 두고, 1) 증상을 규명하고, 2) 원인을 찾고, 3) 예후를 
제시하고, 4) 치료법을 제안하는 과정을 반영하고 있다고 할 수 있다(Germer 등 2005). 결국 불교는 마음에 대한 심리학 이며 우리의 내면을 성찰하여 고통을 해소할 수 있는 가능성 을 제시한다는 측면에서 정신치료와 유사한 면이 많다.

불교에 대한 관심이 커질 수밖에 없는 것은 최근 정신분석 이나 정신치료의 이론과 기법의 변화에서도 확인할 수 있다. 첫째, 정신의학이 종전의 병리학적 현상에 관심을 두고 증상 의 제거에 초점을 두던 시각에서 벗어나 인간의 행복과 안녕 등에 관심을 두는 방향으로 변화한 것이다. 그 결과 실존주 의 심리학, 인본주의 심리학 등이 정신의학에도 영향을 미치 게 되었다. 이런 추세 속에 정신의학이 종교적 의례나 신의 존재, 도그마 등을 요구하지 않으며 인간의 궁극적 성장을 추구하는 불교에 관심을 갖게 된 것은 자연스러운 것이다. 둘째, 심리적 고통의 원인으로 생물학적 기원을 가진 충동 (drive)을 강조하던 초기 정신분석 이론에서 점차 관계(relationship)를 강조하게 된 것이다. 정신분석의 중요한 치료적 개념인 상호주관성(intersubjectivity)은 분석상황을 분석가 와 피분석가의 두 주관적 경험세계 사이의 상호작용이라고 본다(Choi 2010). 이러한 변화는 마음이나 정신도 하나의 과 정이며, 모든 현상은 다만 인연(因緣)에 의해 구성되어지는 것 뿐이라는 연기(緣起)적 관점을 가진 불교에 대한 관심을 증가시키는 데 기여했다.

이런 최근의 정신치료계의 추세를 반영하여 저자는 불교 와 정신치료의 관계를 이해하는 데 중요한 역할을 한 정신 분석가들을 소개하고, 불교와 정신치료의 이론과 실제에서 주목할 만한 몇 가지를 논의하고자 한다.

\section{본 론}

\section{불교에 관심을 둔 정신분석가들}

칼 융(Carl Jung)은 불교에 많은 관심을 갖고 스즈키 선사 의 '선불교 입문(An introduction to Zen Buddhism)'의 서문 을 쓰기도 했다. 이 서문에서 칼 융(Suzuki와 Jung 1948)은 선(禪)에서 말하는 깨달음의 심리학적 의미를 설명하면서, 선의 깨달음과 유사한 경험을 할 수 있는 분야가 바로 정신 치료라고 하였다. 불교에 대한 관심으로 인해 그는 만다라 (Mandala)를 분석심리학에서 중요한 상징적 이미지로 사용 하였다. 융은 "내가 만다라를 그리기 시작했을 때 나는 비로 소 내가 걸은 길, 그 모든 발자취, 내가 행한 모든 것이 다시 금 하나의 점, 즉 중앙에 귀착함을 보았다. 만다라가 중심이 라는 것이 더욱 더 분명해졌다. 그것은 모든 길의 표현이다. 그것은 중앙으로 향하는 길, 즉 개성화(individuation)로의 길이다.”라고 하였다(Rhi 2000).
에리히 프롬(Fromm 등 1960)도 스즈키 선사와의 교류를 통해 불교, 그중에서도 선(禪)불교 사상과 정신분석학의 관 련성을 '선불교와 정신분석(Zen Buddhism and Psychoanalysis')이라는 저서에서 깊이 있게 논하였다. 그는 고통스 러운 증상(symptoms)을 제거하고 사회적 기능을 회복하기 위해 정신분석가를 찾아오는 환자들과 달리, 새로운 많은 환 자들은 사회적으로 기능을 다하고 있어 전통적인 의미의 환 자는 아니나, 삶의 권태나 불안, 내면의 무감각 등으로 인해 고통받고 있다고 했다. 이들의 공통된 고뇌는 자기 자신으로 부터의 소외, 동료로부터의 소외, 자연으로부터의 소외다. 이 들에게 치료는 증상을 제거하여 병이 없는 상태(the absence of illness)가 아니라, 평안한 상태(the presence of well-being) 에 이르는 것이다. 평안한 상태를 프로이트의 개념 안에서 정 의하는 것은 한계가 있으며, 이에 대한 해답을 찾는 데 선불 교 사상이 필요하다. 선은 본질적으로 자기 존재의 본성을 통 찰하는 기술이며, 속박으로부터 벗어나 자유로 가는 길을 열 어준다. 그러므로 선에 대한 이해와 관심은 정신분석의 이론 과 실제에 가장 풍부하고 명쾌한 영향력을 가져다 줄 것이 라고 하였다.

카렌 호나이(Karen Horney)는 자신의 이론을 설명하는 데 도움이 될 수 있는 개념들을 불교에서 발견하고 불교에 많은 관심을 갖게 되었고, 특히 '참된 자기(real self)'가 초기 구조적인(structural) 개념에서 과정(process)을 반영하는 시 간적인(temporal) 개념으로 발전, 변화하는 데 불교의 영향을 많이 받았다고 한다(Westkott 1998).

정신분석과 불교 명상 수행을 병행한 Epstein(1996)은 'Thoughts without a thinker'이라는 저서에서, 붓다의 심리 학적 가르침과 명상의 경험을 정신역동학적 용어로 소개하 고, 프로이트의 논문 '기억, 반복, 그리고 훈습(Remembering, repeating and working-through)'(Freud 1914)을 가지고 붓다 의 가르침이 정신치료의 실제와 어떻게 통합될 수 있는지를 고찰하였다.

\section{무아(無我)와 자기실현}

불교의 핵심 교리는 연기(緣起)라고 할 수 있다. 대승불교 의 공(空)은 그 내용에 있어서 연기와 같은 것이다. 어느 것도 정해진 그 자체가 없이 단지 조건에 의해 생겨나고 조건이 다 하면 소멸할 뿐이라는 것이 연기이다. Jang과 $\operatorname{Kim}(2015 \mathrm{a})$ 의 설명을 빌리면 “나'라고 불리는 것은 오온(五蘊), 즉 색, 수, 상, 행, 식이라는 다섯 요소가 인연에 의해 임시적으로 조화 롭게 결합되어 있는 것에 불과하다. 인연이 다하면 다섯 요 소의 화합도 다하고 '나'도 없어진다. '나'를 구성하고 있는 다섯 요소 가운데 영원하며 변치 않는 것은 하나도 없다. 이 
몸은 언젠가는 사라지고, 기쁨도 잠깐이며 영원한 미움도 없 다. 이 오온이 가화합(假化合)되어 있는 상태를 편의상 '나' 라고 부를 뿐이다. 따라서 영원히 머무르며 변치 않는, 즉 상 주불변(常住不變)의 '나'가 있다는 생각은 착각에 불과하다. 그와 같은 상주불변의 '나'는 없다는 것을 '무아(無我)'라고 한다.”

정신치료에서 자아(ego)나 자기(self)의 개념은 매우 중요 하며 이들의 기능을 강화하는 것이 치료의 과정이기도 하다. 그렇다면 이는 불교의 무아와 대립되는 것인가? 불교의 무 아를 '자아가 없다'는 것이 아니라 '고정된 실체적 자아가 없 다'라는 말로 이해한다면, 이는 정신의학의 관점과 다르지 않다(Germer와 Siegel 2012; Morgan 2010; Williams 1998). 정신분석이나 정신치료에서 말하는 자아도 고정된 자아의 개념이 아닌 역동적인 개념이다(Choe 2004).

Ando(2010)는 "불교의 무아설은 결코 '자아가 존재하지 않는다', '자아가 없다'고 말하는 것이 아니라는 점이다. 그것 은 자아를 실체로 보는 것을 부정하는 것뿐이다. 불교가 부 정하는 자아란 불멸의 영원한 실체로서의 주체일뿐, 생멸 변 화하는 현상적인 주체는 인정하고 있다. 자아는 생각이고, 실체가 아니지만, 실체로서 오인되는 것으로서의 자아는 '있 다'고 볼 수 있다.”라고 하였다.

스즈키(Fromm 등 1960)는 "선은 본질적으로 자기 존재의 본성을 통찰하는 기술이다.”라고 하였는데, 이와 유사한 서술 을 정신분석에서도 찾을 수 있다. 카렌 호나이(Horney 1950) 는 자아실현(self-realization)의 개념에서 "도토리에게 떡갈 나무가 되는 것을 가르칠 필요는 없으며, 또 실제로 가르칠 수도 없다. 하지만 때가 되면 도토리 안에 잠재되어 있던 힘 이 발달될 것이다. 인간 또한 이와 마찬가지로, 시기가 되면 그때 그는 참된 자기(real-self)가 갖는 독자적인 활력을 발 달시킬 것이다.”라고 했다(Ando 2010). 칼 융(Carl Jung)의 개 성화(individuation), 매스로우(Maslow)의 자아실현(selfactualization)도 선에서 추구하는 목적에 부합된다.

도겐 선사(1200 1253)의 “불교를 공부한다는 것은 자신에 대해 공부하는 것이고, 자신에 대해서 공부한다는 것은 자신 을 잊는 것이고, 자신을 잊는다는 것은 일체와 친해지는 것 이다.”는 말은 수행을 통해 자신의 내면을 통찰하여 무아를 알고 결국 이 세상을 연기로 바라보게 된다는 깨달음의 비유 이다.

\section{불교수행(명상)과 정신치료과정}

명상이라는 용어를 불교 수행과 동일한 것으로 엄밀하게 볼 수 없다. 그러나, 여기서는 그러한 논의는 생략하고 불교 수행의 핵심을 훼손하지 않는 범위에서 구별없이 사용할 것
이다. 불교의 수행법인 명상은 크게 사마타(Samatha: 선정 수행)와 위빠사나(Vipassana: 지혜수행)로 나눌 수 있고, 이 러한 초기 불교의 수행이 중국에 전해지면서 시대와 문화적 요구로 새롭게 탄생한 선불교의 수행법이 우리가 흔히 선이 라고 부르는 간화선(看話樿)과 묵조선(黙照禪)이다. 이들은 방법의 차이는 있으나 이 과정에서 흔히 마음챙김(mindfulness)이라고 정의되는 '이 순간에, 어떤 판단도 하지 않고 주 의를 기울이는(Kabat-Zinn 2006)' 것이 반드시 필요하다.

우리는 정신분석이나 정신치료에서도 이와 유사한 개념 을 찾을 수 있다. 프로이트(Freud 1912)는 'evenly hovering attention', 'evenly suspended attention'이라는 개념에서 치 료자는 환자가 하고 있는 말과 치료자 자신의 반응 모두에 깨 어 있고, 수용적이고, 주의를 기울이는 상태를 유지하여야 한 다고 했다. 이런 태도가 결여되면 치료자는 이미 그가 알고 있는 것 외에 어떤 것도 찾아낼 수 없다고 했다. 비온(Bion) 의 'to listen without memory, desire or understanding'이라 는 개념도 치료자는 환자가 어떤 사람인가에 대한 예상이나 치료 중에 무엇이 일어나야 한다는 기대 없이 환자의 말을 들어야 한다는 것으로 프로이트의 개념과 유사한 의미로 해 석할 수 있다(Rubin 2009).

정신분석이나 정신치료에서 환자가 자신의 무의식을 탐색 하고 전이 현상을 이해하는 과정은 치료자와의 관계, 치료자 의 해석 등을 통해 이루어진다. 그런 측면에서 명상 중인 수 행자는 정신치료의 치료자와 환자의 역할을 동시에 하고 있 는 것으로 비유할 수 있다. 수행자는 자신의 마음을 관찰하여 통찰을 얻기 위해 오로지 혼자의 힘으로 집중 속에서 지혜를 얻어야 한다. 물론, 정신치료에서 치료 과정을 보다 심층적 으로 이해하기 위해 지도감독이 필요하듯, 올바른 수행을 위 해서는 명상을 지도해 줄 스승이 반드시 필요하다. 저자가 수행하고 있는 곳에서는 수행자와 스승이 일대일로 만나 수 행 과정을 점검받는 '독참(獨篍'이라는 선의 전통적인 제도 를 유지하고 있다. 오롯이 혼자의 힘으로 자신의 내면과 만나 는 긴 수행의 과정에서 스승에게 자신의 경지를 보이고 점 검을 받지 않는다면, 자기도 모르게 잘못된 길로 수행을 이 어갈 수도 있다.

불교와 정신치료가 마음에 접근하는 방법에서는 유사성 을 찾을 수 있으나, 이러한 접근을 통해 얻은 내용물을 다루 는 방법은 분명 다르다. 정신분석이나 정신치료는 무의식을 의식화하여 얻은 내용물을 해석하는 것이 반드시 필요하다. 위빠사나 명상과 선수행이 다른 방법을 취하긴 하나, 불교의 명상은 모두 생각의 내용을 분석하는 것이 아니라 다만 있 는 그대로 관찰하는 것이라는 공통점이 있다. 정신분석이나 정신치료에서 언어는 매우 중요한 요소이다. 의식화된 무의 
식을 표현하는 것도, 그것을 해석하는 것도 모두 언어이다. 그러나 명상에서는 언어가 필요하지 않다. 심지어 선수행에 서는 언어와 문자를 떠난 자리에서 화두를 참구할 수 있다 고 하고 있다. 이와 관련해서 무문 혜개(1183 1260) 선사는 "말은 사물을 있는 그대로 드러낼 수 없고, 어구(語句)는 진 리 그 자체가 되게 하지 않는다. 말을 그대로 받아들이는 자 는 진실을 잃고, 어구에서 벗어나지 못하는 자는 깨달을 수 없다.”라고 하였다(Jang과 Kim 2015b).

언어와 논리에 익숙한 저자에게 스승은 "선은 불안의 원 인을 분석하는 것이 아니라, 그것을 뛰어 넘는 것이다.”라고 하셨다. 이러한 선의 본질을 잘 표현해주는 화두와 Jang과 $\operatorname{Kim}(2012)$ 의 설명을 소개한다.

달마가 면벽(面壁)하고 있다. 이조(二)가 눈 위에 서서 팔을 자르고 말한다. "제 마음이 편하지 못합니다. 부디 편하게 해 주십시오." 달마가 말한다. "마음을 가지고 오 너라. 편하게 해 주마." 이조가 말한다. "마음을 찾아 보 았으나 끝내 찾을 수가 없습니다." 달마가 말한다. "이미 너의 마음을 편안하게 했느니라."

"찾아도 찾을 수 없다는 것을 알면 찾기를 그만둔다. 찾는 마음이 멈추면 무거운 짐은 저절로 내려진다. 불안의 요소가 없어졌다. 발버둥쳐도 헛일이라는 사실을 명확히 자각하는 것이야말로 안심(安心)이다. 혜가(이조)는 비로소 안심한다. ‘불안하다'거나 ‘안심을 구한다’거나 그런 미혹한 마음이 완 전히 없어져 버렸다. 죄다 없어져 진정 편안한 경지, 이것이 진정한 안심의 세계다. 안심(安心)은 본래의 편안함이다. 마 음을 안심시키는 것이 아니다. 본래의 편안함은 잃어버린 적 이 없어 새삼스레 찾을 필요도 없는 진실한 자기 모습이다. 지옥에서도 극락에서도, 손해를 보아도 큰 병에 걸려도 편안 하다. 일체를 방하했는데 무엇을 상대로 안불안(安不安)이 있겠는가. 오직 편안할 뿐이다. 혜가가 달마에게 구한 것은 단순히 마음을 진정시키는 방법이나 원리가 아니었다. 가장 본래적인, 있는 그대로의 마음에 눈뜨는 것이었다. 불안한 마음을 일시적으로 안정시키는 응병여약(應炳與藥)의 방법 탐구가 아니라, 약이 필요 없는 본래의 자기를 발견하는 것 이다.”(Jang과 Kim 2012).

\section{결 론}

저자는 불교학자도 아니고, 정신분석가도 아니다. 다만 정 신분석을 바탕으로 정신역동적으로 환자를 이해하고자 하 는 정신과 의사이며, 치료자 이전에 한 인간으로서 자신을
이해하기 위해 불교 수행에 입문하였다. 이 과정에서 불교 수행이 환자를 치료하는 데도 도움이 되며, 정신분석이나 정 신치료가 불교를 이해하는 데도, 수행 과정에서 만나는 문제 들을 해결하는 데도 도움이 된다는 것을 자연스럽게 알게 되었다.

이러한 저자의 경험을 불교학자와 정신분석가들의 저서 에서 확인하고자 하는 동기로 이 논문을 시작하였다. 따라서 이 논문은 정신분석의 시각으로 불교를 재해석하자는 시도 가 아니며, 두 분야를 섣불리 통합하려는 시도도 아니다. 다 만 불교의 수행이 정신치료에 어떤 도움을 줄 수 있는지, 정 신분석과 정신치료는 불교 수행에 어떤 도움을 줄 수 있는 지의 답을 찾고자 하는 고민의 과정이라고 할 수 있겠다.

지금까지 저자가 살펴본 바로는 불교와 정신치료는 그 역 사에 비해 체계적으로 학문적 교류가 이루어졌다고 보기 어 렵다. 또한 최근에 주목을 받는 불교적인 심리치료법은 서양 의 심리학적 용어로 불교를 재해석하여 기법과 기술적인 통 합만으로 제한하는 측면도 있을 것이다. 진지한 성찰과 신중 한 학문적 태도로 두 분야의 교류가 이루어져 서로의 본질 적 의미와 가치를 훼손시키지 않으면서 상보적인 역할을 할 수 있기를 기대한다.

\section{Conflicts of Interest}

The author has no financial conflicts of interest.

\section{REFERENCES}

Aich TK. Buddha philosophy and western psychology. Indian J Psychiatry 2013;55(Suppl 2):S165-S170.

Ando O. Buddhism as psychotherapy. Seoul: Bulkwang;2010.

Choe HD. Neuropsychiatric considerations on the Buddhist doctrine of 'non-self'. Engaged Buddhism 2004;18:157-165.

Choi YM. History of psychoanalysis-focus on the evolution of theories. J Korean Nueropsychiatr Assoc 2010;49 Suppl 1:S9-S35.

Epstein M. Thoughts without a thinker. London: Duckworth;1996.

Freud S. Recommendations to physicians practicing psychoanalysis. London: Hogarth Press; 1912.

Freud S. Remembering, repeating and working-through. London: Hogarth Press;1914. p.147-156.

Fromm E, Suzuki DT, de Martino R. Zen Buddhism and Psychoanalysis. New York: Harper; 1960.

Germer CK, Siegel RD. Wisdom and compassion in psychotherapy: deepening mindfulness in clinical practice. New York: Guilford Press;2012

Germer CK, Siegel RD, Fulton PR. Mindfulness and psychotherapy. New York: Guilford Press;2005.

Horney K. Neurosis and human growth. New York: Norton;1950.

Jang HO, Kim SU. Rendezvous with Buddhism. Bulkwang 2015a;5:78-83.

Jang HO, Kim SU. Rendezvous with Buddhism. Bulkwang 2015b;11:52-57.

Jang HO, Kim SU. Zen comment on the Mumungwan. Seoul: Minjoksa; 2012. p.328-336.

Kabat-Zinn J. Mindfulness for beginners. Boulder, CO: Sounds True; 2006.

Michalon M. "Selflessness" in the service of the ego: contributions, limitations and dangers of Buddhist psychology for western psychother- 
apy. Am J Psychother 2001;55:202-218.

Morgan H. Self and No-Self: Continuing the dialogue between Buddhism and psychotherapy edited by MATHERS, DALE, MILLER, MELVIN E. \& ANDO, OSAMU. J Anal Psychol 2010;55:726-738.

Porter K. Is there something happening here? Buddhism and psychoanalysis. Psychoanal Perspect 2004;2:91-100.

Rhi BY. Analytical psychology: C.G.Jung's thoughts on mind. Seoul: Ilchokak publishing co.;2000.
Rubin JB. Deepening psychoanalytic listening: the marriage of Buddha and Freud. Am J Psychoanal 2009;69:93-105.

Suzuki DT, Jung CG. An introduction to Zen Buddhism. New York: Grove Press; 1948.

Westkott M. Horney, Zen, and the real self. Am J Psychoanal 1998;58: 287-301.

Williams P. Nina, Anatta and 'no-self'. Br J Psychother 1998;14:527530. 